Pérez Martínez, Henar.

Universidad de Cádiz: Doctorando en Arte y Humanidades, Línea de investigación Filosofía,

Democracia e Identidades.

\title{
El artista radicante como etnógrafo. Sus prácticas y sus recorridos.
}

\section{The radicant artist as ethnographer. Practices and tours.}

\author{
TIPO DE TRABAJO: \\ Comunicación virtual. \\ PALABRAS CLAVE: \\ Arte global, radicante, giro etnográfico, nomadismo artístico, identidad cultural.
}

KEY WORDS:

Global art, radicant, ethnographic turn, artistic nomadism, cultural identity.

\section{RESUMEN}

El artista radicante es constitutivo de la era del arte global en que la identificación cultural y la distinción identitaria se convierten en factores determinantes de la actualidad. La presente investigación busca, así, contribuir al esclarecimiento del radicante como figura subsumida a la contemporaneidad.

El texto consta de cuatro partes fundamentales. La primera a modo de introducción contextualiza el objeto estudiado. Este contexto se inicia con el fin de la Guerra Fría, coincidiendo con el desarrollo de movimientos sociales y corrientes de pensamiento que amparan la liberación de países subyugados, la igualdad y la defensa de los derechos humanos; y se extiende hasta la actualidad. En segundo lugar, se analiza el cambio de la concepción social de la figura del artista que se desenvuelve en el entorno global, teniendo como propósito la justificación de su influyente papel en la construcción de identidades culturales múltiples, asumiendo un rol antropológico y etnográfico que solo los artistas pueden resolver de forma libre y sin coerciones sociales. En tercer lugar y para aclarar los argumentos expuestos, se muestran ejemplos de manifestaciones artísticas de autores de gran reconocimiento que coinciden con la definición propuesta de artista radicante (interiorizan experiencias culturales diversas y las integran) y que producen obra de calado etnográfico. Asimismo, en este apartado se aclaran, evalúan y analizan las categorías de radicante que el ideólogo del término (aplicado al arte y los artistas) Nicolas Bourriaud, propone. Por último y muy brevemente, se exponen las conclusiones de esta investigación cualitativa.

\section{ABSTRACT}

The radicant artist is an important component of the global art age, when cultural identification and identity projected difference become a decisive factor nowadays. The present study is searching for clarify the radicant as a leading figure of contemporaneity.

This text consist of four parts. The former, as introduction, contextualize the study objective. The end of the Cold War is the starting point, coinciding with the development of social movements and schools of thought that support the subjugated countries liberation, the equality and the human right defence. Thus, this moment spread to the present. Secondly, the social conception of the artist in the global environment is analysed, having as its purpose the proof of its influential function for multiple cultural identities construction. The artist figure assume an anthropologic and ethnographic role that only the artist can solve without social coercion and freely. In the third place, and to shed light on the previous arguments, artistic performances of mainstream artists who have been here identify as radicant artist (they are able to internalise and integrate diverse cultural experiences) are shown. Likewise, the radicant categories displayed 
by the term ideologist, Nicolas Bourriaud, are evaluated, analysed and cleared up. Finally and briefly, the conclusions of this qualitative research are presented.

\section{CONTENIDO}

\section{INTRODUCCIÓN}

El arte de la era global tiene como marca histórica inicial la caída del muro de Berlín y previamente el nacimiento de movimientos sociales que reivindican la igualdad entre los hombres y los derechos humanos, como "Negritud" o el "Movimiento de Países No Alineados", estos movimientos luchan en contra del mecenazgo ideológico que salvaguarda el occidente hegemónico.

En el arte occidental del siglo XX hay numerosos movimientos que aluden al primitivismo del "otro". El arte naif que trata de expresarse desde la mirada y el sentir de un niño aún por descubrir el mundo; el primitivismo que muestra su deseo de manifestarse como el otro no condicionado por la cultura occidental; en el surrealismo, el otro se revela a través del subconsciente; mientras que en movimientos como el expresionismo abstracto, el informalismo en Europa o el art brut, el autor se desinhibe e identifica con el otro por medio de una gestualidad aparentemente espontánea. Sin embargo, en el arte de la era global, el giro etnográfico se distingue de estos movimientos por la autoconciencia de sí mismo y la integración de las especificidades culturales.

Con la llegada de la era posindustrial se transforman las estructuras de trabajo tradicionales, las actividades laborales se deslocalizan y se expanden de forma horizontal; ahora, la generación de redes internacionales de contactos ha perdido su halo simbólico (Gielen 2014) y la expresión artística y la cultura no son ajenas a este fenómeno. El giro etnográfico del arte global se amolda perfectamente a esta forma de trabajar horizontal, el creador elige un lugar, se empapa de su cultura, aprende su lengua y sus costumbres, plantea un proyecto y solo cuando haya sido realizado selecciona un nuevo destino y da comienzo a un nuevo ciclo. El artista (radicante) como etnógrafo no solo mapea un sitio, sino que también trabaja en términos de tópicos, marcos, etc. (Foster 2001, p. 206).

\section{¿ARTISTA, ETNÓGRAFO O NÓMADA?}

Walter Benjamin indicaba en El autor como productor (2004) que el artista debía estar comprometido con su tiempo, invitaba a los artistas de izquierdas a unirse al proletariado con el fin de superar la cultura y el arte burgués. Sin embargo, los movimientos revolucionarios de trabajadores situaban al trabajador como un otro pasivo. A este respecto, Hal Foster (2001) apunta que en el arte avanzado de izquierdas ha surgido un paradigma estructuralmente semejante al modelo identificado por Benjamin, el artista como etnógrafo, posición que le permite ser percibido o no como un otro cultural. Este artista se levanta en nombre del otro cultural o étnico en lugar de por el proletariado, se produce un desplazamiento de los temas centrales del arte, pasando del giro políticoeconómico (brecha entre el capitalismo y el comunismo) a la identidad cultural. Más sencillamente, se traslada la problemática de lo social a lo cultural o antropológico. En este sentido Foster afirma en su texto de 1994 El artista como etnógrafo que al artista se le puede pedir que asuma los papeles de nativo e informante así como de etnógrafo $(2001$, p. 178). Los artistas, críticos de arte y comisarios pueden realizar trabajos de campo contextuales poniéndose en el papel de semiólogos culturales. Foster asevera que solo ellos pueden resolver estos modelos contradictorios mágicamente (...) pueden continuar y condenar la teoría crítica, pueden relativizar y recentrar el sujeto, todo al mismo tiempo (2001, p. 187).

Por otra parte, el etnógrafo, por su función, está en peligro de caer en contradicciones, es subversivo con lo suyo, se rebela contra sus tradiciones y se muestra respetuoso si la sociedad o cultura que encara se manifiesta diferente a la propia (Lévi-Strauss 1988); siendo así, solo el artista puede resolver este conflicto actuando "libremente". La etnicidad a diferencia de cualquier otra característica humana, tiene la ventaja de mostrar lo cultural como un hecho de la naturaleza y la libertad como una necesidad (Bauman 2006). La pertenencia a un grupo étnico-cultural induce a la acción, debemos elegir ser fieles a nuestra naturaleza, esforzarnos por preservar el modelo establecido generalmente por otros. De este modo, la alteridad se define desde el lado puesto, uno mismo no puede reconocerse como otro.

El más insigne antropólogo cultural del siglo XX, Claude Lévi-Strauss, señaló en Tristes Trópicos que existían dos actitudes propias del etnógrafo: es crítico a domicilio y conformista fuera (1988, p. 440). Por el contrario, el artista está totalmente inmerso, no toma la misma actitud analítico-crítica que el etnógrafo y es capaz de generar un impacto social. Entonces, la diferencia esencial entre ambos radica, como apuntó Joseph Kosuth en su ensayo The artist as anthropologist (1991), en que al etnógrafo le preocupa sentir desenvoltura en otra cultura, mientras que el artista procura sentirse libre en la suya propia, profesando como suya aquella que le acoge.

Pese a esto, una sobreidentificación con el otro puede comprometer la otredad, por ejemplo, la izquierda identifica al otro como víctima. En ocasiones, la crítica occidental muestra su incomodidad frente a imágenes que representan historias cruentas y desoladoras de los otros de un modo "estetizado", utilizando recursos de obstrucción visual y ocultación, véase el proyecto del artista chileno Alfredo Jaar sobre las minas de oro brasileñas de Sierra Pelada, Gold in the morning de 1985 o la serie sobre el genocidio de Ruanda, The Rwanda Project en 1994. Esa visión de la crítica está asentada en una concepción artificial, parcial y alterada 
genéticamente de los hechos que está al servicio de los intereses de los dominantes frente al sujeto subalterno. El error reside en la victimización de la víctima.

Esta privilegiada posición que ostenta el artista como autoridad cultural puede desembocar en dos vertientes conductuales. La primera y más anclada a la tradición artística está marcada por el sesgo primitivista ya mencionado, o por la búsqueda de lo exótico. El ejemplo más recurrente de este primer caso es la huida de Gauguin a la Polinesia francesa (Sánchez Durá 2001). Y en segundo lugar, artistas que, de un modo más eficaz, aprovechan la oportunidad para colaborar con diversas comunidades culturales de forma innovadora; recuperan historias suprimidas que son visibilizadas y puestas en escena de un modo congénito. No obstante, el papel antropológico otorgado al artista puede suponer un cuestionamiento de la autoridad etnográfica y una crítica institucional (Foster 2001).

\section{PRÁCTICAS Y RECORRIDOS ERRÁTICOS}

Cabe identificar el calificativo de radicante en cuanto al artista como un semiólogo capaz de insertarse y arraigarse en culturas diversas conformando relatos de lo vivido por su, ahora, comunidad cultural. Según Bourriaud el término radicante designa a un sujeto afligido por la necesidad de un vínculo con su entorno y las fuerzas del desarraigo, por la contraposición entre la globalización y la singularidad, entre la identidad y el aprendizaje del Otro (2009, p. 57). El artista radicante no desestima sus creencias, ideas o culturas originarias sino que las transcodifica y las pone en escena en contextos y formatos heterogéneos, tales actitudes son propias de los nómadas.

Por otra parte, Bauman señala que:

Los eremitas fueron los primeros que vivieron de principio a fin la experiencia del yo "descontextualizado" y "libre de trabas". Eran como dioses porque todo lo que hacían lo hacían "ab nihilo". Su peregrinaje hacia Dios era un ejercicio de autoconstrucción (2003, p. 44-45)

Del mismo modo, el artista radicante se configura conforme avanza en su trayecto, va haciendo crecer sus raíces y generando nuevos significados híbridos.

En la conferencia celebrada en 1994 De peregrino a turista, o una breve historia de la identidad el renombrado sociólogo Zygmunt Bauman analiza los sucesores del eremita distinguiendo entre el peregrino, el paseante, el vagabundo, el turista y el jugador (2003). Todos ellos, junto al inmigrante, son figuras dominantes de la cultura contemporánea, pero ninguno se identifica con el radicante pues el recuerdo de su llegada está demasiado presente como para considerársele un ser asentado. Los movimientos del peregrino son demasiado previsibles, el camino viene marcado y no da lugar a desviación. El paseante observa. El vagabundo erra sin hallar acogida. Mientras, el turista viaja movido por su afán de zambullirse en lo extraño, su experiencia está trazada por criterios puramente complacientes y estéticos y emerge de ella antes de ver su dermis impregnada por la identidad del otro.

En una búsqueda de su identidad, el artista Francis Alÿs se inmiscuye como "turista" entre trabajadores de distinta índole, electricistas, fontaneros, etcétera, que anuncian sus servicios en una avenida central de la Ciudad de México. En su proyecto Turista (1994) acoge las formas de comunicación del pueblo con el que convive y las hace igualmente suyas.

Para designar esta nueva figura del artista cuya identidad muta y se renueva constantemente, Bourriaud ha localizado el término "semionauta". El semionauta es:

El creador de recorridos dentro de un paisaje de signos. Habitantes de un mundo fragmentado, en que los objetos y las formas abandonan el lecho de su cultura de origen para diseminarse por el espacio global, ellos o ellas erran a la búsqueda de conexiones que establecer. Indígenas de un territorio sin límite a priori, se ven ubicados en la posición de un cazador-recolector de antaño, del nómada que produce su universo al recorrer incansablemente el espacio (2009, p. 117).

De tal manera, el crítico de arte francés establece diferencias entre estos nómadas artísticos en base a sus "formas-trayectos". Sin embargo, la determinación y acotación de los rasgos identificativos de cada una de las tipologías de arte y artista radicante peca de cierta ambigüedad, ya que en todas ellas se producen correspondencias y trasposiciones de acontecimientos, lugares y tiempos.

La primera es calificada como expediciones y desfiles, refiriéndose, quizá, a aquellos artistas exploradores en que el viaje se convierte en una forma artística en sí. Hoy, el viaje está omnipresente en las manifestaciones artísticas bien por su iconografía o por sus métodos, esta primera genealogía de arte radicante tiene un afán explorador en escenarios aparentemente ya descubiertos. Estas prácticas suponen un desplazamiento entre los signos que generan la experiencia contemporánea de la movilidad. Creadores de recorridos efímeros que cederán a su pronta obsolescencia en tiempo, espacio y forma.

La topología es la segunda de las categorías de radicante que señala, refiriéndose a aquellos artistas que se transformaron en el prototipo de viajero contemporáneo y que conlleva la aparición del trayecto como un principio compositivo de la práctica artística. La característica común de estas obras debe ser la dispersión espacio-temporal que implica la construcción de códigos nuevos, manifestándose estos mediante recorridos o trayectos en vez de en un espacio o tiempo fijo.

En tercer lugar, ubica las bifurcaciones temporales, las modas o tendencias han dejado de sucederse ya no representan marcadores temporales sino producciones transitorias e inestables que se generan indiferentemente en tiempo y espacio. El arte actual se refiere, 
entonces, a nuestra relación con la historia. Una historia que se manifiesta mediante micro relatos subjetivos e irrepetibles de historias presentes, pasadas o ficticias.

Pese a esta voluntad de estratificación, resulta innegable lo difuso de los márgenes de estos paradigmas, pues las tres condiciones se pueden encontrar de forma simultánea en una práctica artística o en la intención y actitud de su creador.

En 1998, Rirkrit Tiravanija (artista de nacionalidad argentina y de ascendencia tailandesa quien cumple a la perfección con las propiedades adjudicadas a la noción de semionauta) invitó a cinco estudiantes de Bellas Artes de la Universidad de Chiang Mai (Tailandia) a realizar una gira turística durante seis semanas en autocaravana por los Estados Unidos, con el fin de descubrir los lugares icónicos de la cultura norteamericana; símbolos como Disneyland, el Gran Cañón o el lugar de nacimiento de Lincoln. De forma sincrónica, la acción se exhibía "en vivo" en el Museo de Filadelfia, de modo que los espectadores podían observar el desplazamiento espacio-temporal a través de una web o emisión vía satélite. Este proyecto Untitled 1998. (On the road with Jiew, Jeaw, Jieb, Sri and Moo), reúne cada taxón de la clasificación que Bourriaud desarrolla de radicante: lo topográfico, la expedición y la dispersión temporal.

Esta acción incluía el viaje, el descubrimiento de un entorno sociocultural distinto al propio basándose tanto en mitos como en hechos, la experimentación de lo topográfico y el conocimiento de espacios y tiempos múltiples asumiendo el rol de turista. De forma simultánea a su producción, la acción se documentaba en grabaciones, fotografías, souvenirs, y obras de arte que fueron creadas a lo largo del viaje. Igualmente, se compartía esta experiencia con terceras personas localizadas en otro espacio y que podían mantener su interés y observarles el tiempo que eligiesen, conservando en su memoria fragmentos de su propia percepción de una vivencia de los otros en lo que se presupone su cultura.

\section{CONCLUSIONES}

Los individuos de la sociedad actual globalizada tienen la continua necesidad de identificarse, de proyectar la propia imagen y reconocerse en ella, pero esta acción resulta cada vez más ardua, pues las identidades no son estáticas, sino que se transforman a la vez el individuo experimenta, aprende y avanza. Por ello, se deduce más abarcable un ejercicio de búsqueda de la diferencia.

La búsqueda de identidad es la lucha constante por detener el flujo, por solidificar lo fluido, por dar forma a lo informe. Nos debatimos tratando de negar o al menos de encubrir la pavorosa fluidez que reina debajo del envoltorio de la forma; tratamos de apartar los ojos de visiones que esos ojos no pueden penetrar ni absorber. Sin embargo, lejos de disminuir el flujo, por no hablar de detenerlo, las identidades son semejantes a la costra que se endurece una y otra vez encima de la lava volcánica, que vuelve a fundirse y disolverse antes de haber tenido tiempo de enfriarse y solidificarse (Bauman 2006, p. 89).

La estética errante tiene que ver con la rápida obsolescencia y la constante regeneración en la que se desvanecen, no solo las obras de arte sino, cualquier cosa que está diseñada o destinada a una existencia en un espacio determinado de tiempo, sufriendo mutaciones paulatinas y adaptaciones a sus nuevos entornos y contextos. Así, la incesante renovación de lo simbólico y lo estético se adivina una característica principal de la sociedad actual.

El artista radicante contribuye a la construcción de identidades híbridas con la libertad de la que carece el etnógrafo. Proporciona soluciones a experiencias culturales diversas y complejas que se fusionan inevitablemente. Estas manifestaciones no pueden ser encasilladas en compartimentos estancos, pues se producirán infinidad de filtraciones y escapes difícilmente controlables que confluirán y se manifestarán en inéditas culturas heterogéneas.

\section{FUENTES REFERENCIALES.}

BAUMAN, Z., 2003. De peregrino a turista, o una breve historia de la identidad. En: P. du HALL, STUART; GAY (ed.), Cuestiones de Identidad Cultural. Madrid: Amorrortu, pp. 40-68. ISBN 950-518-654-1.

BAUMAN, Z., 2006. Modernidad líquida. Buenos Aires: Fondo de la Cultura Económica. ISBN 9505575130.

BENJAMIN, W., 2004. El autor como productor. México DF: Itaca. ISBN 9789687943541.

BOURRIAUD, N., 2009. Radicante. Buenos Aires: Adirana Hidalgo Editora. ISBN 9789871556120.

FOSTER, H., 2001. El artista como etnógrafo. El retorno de lo real. La vanguardia a finales del siglo. Madrid: Akal, ISBN 9788446013297.

GIELEN, P., 2014. El murmullo de la multitud artística. Arte global, política y posfordismo. Madrid: Brumaria. ISBN 978-84-939935-6-6. 
Pérez Martínez, Henar

El artista radicante como etnógrafo. Sus prácticas y sus recorridos

III CONGRESO INTERNACIONAL DE INVESTIGACIÓN EN ARTES VISUALES :: ANIAV 2017 :: GLOCAL [codificar, mediar, transformar, vivir] http://dx.doi.org/10.4995/ANIAV.2017.4868

KOSUTH, J., GUERCIO, G. y LYOTARD, J.-F., 1991. Art after Philosophy and After: Collected Writings, 1966-1990. Cambridge, Massachusetts, London: The MIT Press. ISBN 0-262-11157-8.

LÉVI-STRAUSS, C., 1988. Tristes Trópicos. Barcelona: Paidós. ISBN 9872001863.

SÁNCHEZ DURÁ, N., 2001. ¿El artista como etnógrafo?: El caso Gauguin, tan lejos, tan cerca. Eu-topías. Revista de interculturalidad, comunicación y estudios europeos, vol. 189, pp. 1-27. 